\title{
Wind Characteristics of High-rise Building with Partial Opening
}

\author{
Weibin YUAN \\ College of Civil Engineering and Architecture \\ Zhejiang University of Technology \\ Key Laboratory of Civil Engineering Structures \& Disaster \\ Prevention and Mitigation Technology of Zhejiang Province \\ Hangzhou, China \\ e-mail: yuanwb@zjut.edu.cn
}

\author{
Kexing FAN \\ College of Civil Engineering and Architecture \\ Zhejiang University of Technology \\ Hangzhou, China \\ e-mail: zjfkx00@163.com
}

\author{
Zhao WANG \\ College of Civil Engineering and Architecture \\ Zhejiang University of Technology, \\ Hangzhou, China \\ e-mail:732518269@qq.com
}

\begin{abstract}
The paper discusses the wind pressure distributions on high-rice buildings with partial openings by means of wind tunnel tests and numerical simulations. The wind tunnel tests were carried out in the boundary layer wind tunnel over an urban terrain with a geometric scale. The numerical simulations used the method of SIMPLEC algorithm and the turbulence model, in which a realizable $\kappa-\varepsilon$ model was used to simulate the pressure coefficient and the wind environment surrounding the partial openings. Detailed analyses of wind pressure coefficients for buildings of three different opening cases are presented. The results show that the pressure coefficients are different on the two sides of the opening and the distribution of wind velocity surrounding the opening is remarkably affected by the opening size. Moreover, the wind speed reaches the maximum in the opening when the wind direction is $45^{\circ}$. This suggests that there is a potential to utilize the wind energy by placing wind turbines in the partial opening of the high-rise buildings.
\end{abstract}

Keywords-partial openings; wind tunnel test; numerical simulation; wind turbine; wind environment

\section{INTRODUCTION}

The development of low-carbon city is an inevitable tendency to guarantee the harmonious coexistence of human and environment. In China most cities are now facing with a shortage of energy. As a consequence, the development of renewable energy in urban buildings has become an important part of the architectural design, especially for high-rise buildings. Wind power, as a renewable and clean energy, is usually the first choice of renewable energy sources in building design. To achieve this, however, the designer has to have the knowledge of wind and its effect on structures of the high-rise buildings of different shapes.

The subject of wind loads on rectangular high-rise building has been an active topic and attracts many researchers (Kareen [1]; Kwon and Kareen [2]; Katagiri et al. [3]). Although some previous studies (Holmes [4]; Ho etal. [5]; Sharma and Richards [6]; James et al. [7]; Joachim et al.
[8]) have shown that wind pressure in a building can be affected by partial opening, and there are not many works on wind-induced response of high-rise buildings with partial opening. In recent years, the use of wind power (Bayoumi et al. [9]; Lu and Sun [10]) has become as one of the most interesting research topics. For example, Li et al. [11] discussed the results obtained from a combined wind tunnel and full-scale study of wind effects on super tall buildings. Chan et al. [12] reported a set of techniques of wind load integration for asymmetrical tall building under crosswind windward load. Guhan et al. [13] estimated the ratio of internal and external pressure fluctuations based on the simplified model of buildings with partial openings. Lam et al. [14] investigated the wind induced interference effects between two high-rise buildings by measuring the pulsating wind load on the buildings.

Wind tunnel tests have been widely used to study the characteristics of building under the action of wind loads in several decades. Gu et al. [15] analyzed the mean and fluctuating wind pressure distributions on a complicated group-tower by wind tunnel tests. Their experimental data showed that the pressure distributions along the height of each sub-tower were quite complicated. With the improvement of CFD software, numerical simulation has become an efficient way to justify the reliability of wind tunnel tests. In recent years many new computational methods have been developed to improve the accuracy of numerical simu lations in various different situations. Li et al. [16] analy zed the wind loads on tall build ings and the wind speed up factors in tunnels for wind-power generation using wind tunnel tests and wind climate data analysis. Ramponi and Blocken [17] analyzed the effect of simulation parameters used in CFD simulations on the reliability and accuracy of the obtained simulation results.

A large number of experiments have also been done on the wind power utilization of high-rise buildings. However, most of them are not for high-rise buildings with partial openings. In this paper, the wind tunnel tests and numerical 
simulations were performed to investigate the wind load on high-rise buildings with partial opening. The results obtained from the wind tunnel tests and numerical simulations are compared to demonstrate the reliability and accuracy of the numerical simulation. The present work can be used as the guidance for the monitoring of wind induced internal pressure response of high-rise buildings with partial opening, where wind turbines could be installed for power generation.

\section{EXPERIMENT}

\section{A. Boundary Layer Flow and Model Characteristics}

Test models with three different opening sizes denoted as M1, M2, and M3 were designed. The dimension of the test models is $200 \mathrm{~mm}$ (long) $\times 100 \mathrm{~mm}$ (wide) $\times 600 \mathrm{~mm}$ (high) The wind tunnel test was conducted in the boundary layer wind tunnel, which has the dimension of $18 \mathrm{~m}$ (long) $\times 6 \mathrm{~m}$ (wide) $\times 3 \mathrm{~m}$ (high). The blockage ratio of the model tests is less than $3 \%$. The maximum wind speed in the wind tunnel is $55 \mathrm{~m} / \mathrm{s}$. Atmospheric boundary layer on different terrains required by the reduced scale model was obtained by using spires and roughness elements set on the floor in the wind tunnel. The models were made of organic glass with a geometric scale of 1:300 with two different wind directions $\left(\theta=0^{\circ}, 45^{\circ}\right)$. According to the requirement in the wind tunnel test, wind pressures were measured by pressure taps (outer diameter of $1.6 \mathrm{~mm}$ ), which were arranged vertically to story $\mathrm{F}$ along the building height and connected to the electronic pressure scanner.

\section{B. Wind Field Simulation}

Considering the features of landform and physiognomy surrounding the building, spires and roughness elements were used to simulate the boundary layer wind flow in the Loads Standard Code of China (GB5009-2012) as exposure category B with a roughness exponent of $\alpha=0.15$.

\section{NUMERICAL SIMULATION}

\section{A. Governing Equations}

The goveming equations of incompressible turbulent wind flow around a building are presented by the Reynolds-averaged Navier-Stokes equations as follows:

$$
\begin{gathered}
\frac{\partial u_{i}}{\partial x_{i}}=0 \\
\frac{\partial u_{i}}{\partial t}+u_{j} \frac{\partial u_{i}}{\partial x_{j}}=-\frac{1}{\rho} \frac{\partial p}{\partial x_{i}}+\frac{\partial}{\partial x_{j}}\left[\eta\left(\frac{\partial u_{i}}{\partial x_{j}}+\frac{\partial u_{j}}{\partial x_{i}}\right)-\overline{u_{i}^{\prime} u_{j}^{\prime}}\right]
\end{gathered}
$$

where $i, j=1,2,3$ represent the three coordinate axes, $u_{1}, u_{2}$ and $u_{3}$ are the three components of velocity along $x_{1}, x_{2}$ and $x_{3}$ axes of the Cartesian coordinate system, $\rho$ is the density, $\mathrm{p}$ is the pressure, $t$ is the time, $\eta=\mu / \rho$ is the Kinematic viscosity, and $\mu$ is the dynamic $v$ iscosity.

The standard $\kappa-\varepsilon$ model of the turbulent kinetic energy is expressed as follows:

$$
\frac{\partial k}{\partial t}+u_{j} \frac{\partial k}{\partial x_{j}}=\eta_{t} \frac{\partial u_{i}}{\partial x_{j}}\left(\frac{\partial u_{i}}{\partial x_{j}}+\frac{\partial u_{j}}{\partial x_{i}}\right)-\frac{\partial}{\partial x_{j}}\left[\left(\eta+\frac{\eta_{t}}{\sigma_{k}}\right) \frac{\partial k}{\partial x_{j}}\right]-\varepsilon
$$

Where $k=\frac{1}{2} u_{i} u_{i}, \varepsilon=\eta \frac{\partial u_{i}}{\partial x_{j}} \frac{\partial u_{j}}{\partial x_{i}}$ and $\eta_{t}=C_{\mu} \frac{k^{2}}{\varepsilon}$ is the turbulent kinetic energy, the turbulent kinetic energy dissipation and the turbulent kinematic viscosity coefficient, respectively. The transport equation of turbulent kinetic energy dissipation can be is expressed as follows:

$$
\frac{\partial \varepsilon}{\partial t}+u_{j} \frac{\partial \varepsilon}{\partial x_{j}}=\frac{C_{1} \varepsilon}{k} \eta_{t} \frac{\partial u_{i}}{\partial x_{j}}\left(\frac{\partial u_{i}}{\partial x_{j}}+\frac{\partial u_{j}}{\partial x_{i}}\right)-\frac{\partial}{\partial x_{j}}\left[\left(\eta+\frac{\eta_{t}}{\sigma_{\varepsilon}}\right) \frac{\partial \varepsilon}{\partial x_{j}}\right]-C_{2} \frac{\varepsilon^{2}}{k}
$$

Where $C_{\mu}=0.09, \sigma_{\kappa}=1.0, \sigma_{\varepsilon}=1.3, C_{1}=1.44$, and $C_{2}=1.92$ are the dimensionless coefficients of standard $\kappa-\varepsilon$ model [18].

\section{B. Geometry Setting}

To be comparable with the wind tunnel test, the dimension of the full scale model used in the simulation is chosen as $60 \mathrm{~m}$ (long) $\times 30 \mathrm{~m}$ (wide) $\times 180 \mathrm{~m}$ (high). Based on different partial openings, five simulation models, namely S1, S2, S3, S4 and S5, were established (see Table.1), which represent different $K / L$ ratios where $K$ is the width of opening and $L$ is the length of the longer side of the building.

\section{Computational Domain}

The computational domain and unstructured meshes are presented in Fig.1, in which the highness of the domain is $5 \mathrm{H}$ ( $\mathrm{H}$ is the building height), the width of the domain is $5 \mathrm{D}$ (D is the characteristic length of the building), and the length of the domain is $16 \mathrm{D}$ (5D in front of the building where wind is applied and 10D in rear of the building). The blockage ratio for the model tests is less than $3 \%$.

\section{Boundary Condition}

The following boundary conditions were assumed in the simulations:

1) The inlet velocity and turbulence intensity are determined according to the wind tunnel test;

2) The exponent $\alpha$ that varies with roughness is 0.15 ;

3) Turbulence intensity is $I_{(10)}=0.14$ at reference height;

4) The outlet pressure is zero, meaning free flow;

5) Symmetrical boundary conditions are applied on the two side surfaces and the top surface;

6) All surfaces are as sumed to be no-s lip surface.

The simulation was performed using the commercial software - Fluent 14.5. In order to ensure the Courant number is less than 1 , the smallest grid size was chosen as $0.005 \mathrm{~m}$ and the time step was chosen as $0.0001 \mathrm{~s}$. The governing equations were solved numerically by using the SIMPLEC algorith $m$ and the two-order upwind scheme for momentum, turbulent kinetic energy, and dissipation rate. 


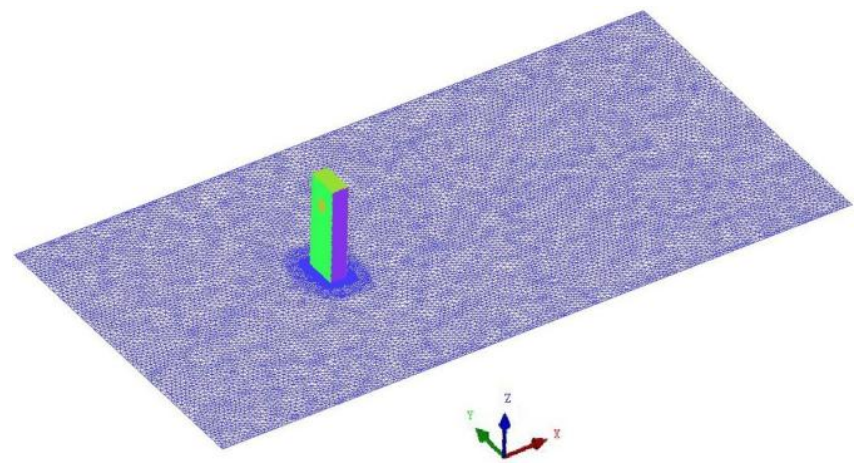

Figure 1. Domain used in the simulations

TABLE I. MODEL PARAMETERS

\begin{tabular}{|c|c|c|c|}
\hline Model & $\mathrm{L} \times \mathrm{B} \times \mathrm{H}$ & Openings setting & $K / L$ \\
\hline $\mathrm{S} 1$ & $60 \mathrm{~m} \times 30 \mathrm{~m} \times 180 \mathrm{~m}$ & complete wall & 0 \\
\hline $\mathrm{S} 2$ & $60 \mathrm{~m} \times 30 \mathrm{~m} \times 180 \mathrm{~m}$ & $\begin{array}{l}\text { Opening in the } \\
\text { short side wall }\end{array}$ & $30 \%$ \\
\hline $\mathrm{S} 3$ & $60 \mathrm{~m} \times 30 \mathrm{~m} \times 180 \mathrm{~m}$ & $\begin{array}{l}\text { Opening in the } \\
\text { long side wall }\end{array}$ & $30 \%$ \\
\hline S4 & $60 \mathrm{~m} \times 30 \mathrm{~m} \times 180 \mathrm{~m}$ & $\begin{array}{l}\text { Opening in the } \\
\text { long side wall }\end{array}$ & $20 \%$ \\
\hline S5 & $60 \mathrm{~m} \times 30 \mathrm{~m} \times 180 \mathrm{~m}$ & $\begin{array}{l}\text { Opening in the } \\
\text { long side wall }\end{array}$ & $40 \%$ \\
\hline
\end{tabular}

IV. RESULTS AND DISCUSSION

\section{A. Validity of the Simulation}

Fig.2 shows the distributions of wind pressure coefficient of M1, M2 and M3 at story F obtained from the wind tunnel tests for two different wind directions (i.e. cases 1 to 2). It can be seen from the figure that, the coefficients of M1, M2 and M3 are very close in case one (Fig.2a), indicating that the opening has negligible influence on the wind pressure coefficient if the wind is either parallel or normal to the surface of the opening. As it is expected, the wind pressure coefficient is positive on the upwind surface and negative on the rear and side surfaces. The distribution of the wind pressure is symmetric about the symmetrical axis of the building parallel to the wind direction. However, when the wind is inclined to the surface of the opening (case 2) the wind pressure coefficients are different between the buildings with and without opening. For case 2, it is found that the wind pressure difference between M1 and M2 or between M1 and M3 is mainly on the upwind surfaces, whereas on the leeward surfaces the difference is rather small. Also, it can be observed from Fig. 2 that, with the increased wind inclined angle, the region with positive pressure coefficient in the building increases too.

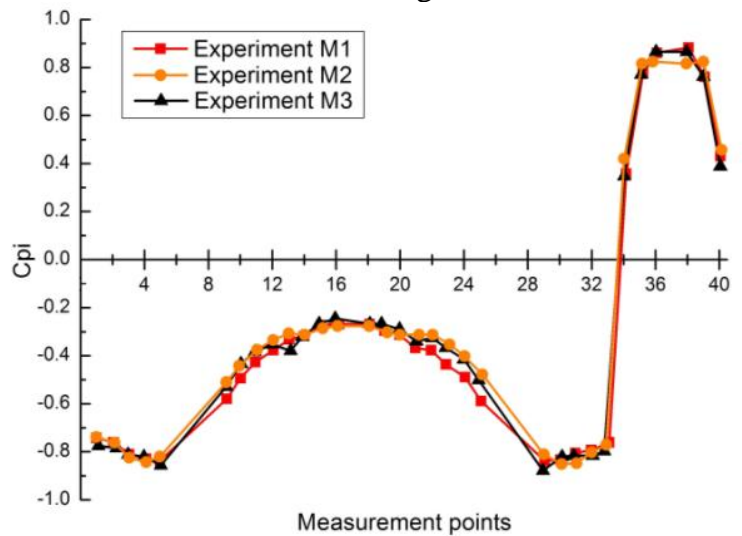

(a)

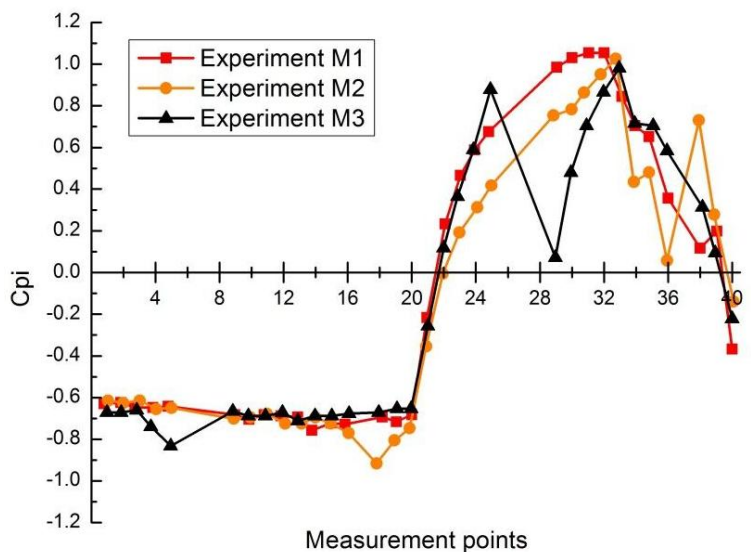

(b)

Figure 2. Wind pressure coefficient (Cpi) distribution at story $\mathrm{F}$ for different wind directions. (a) case 1 and (b) case 2

The wind pressure coeffic ient distribution curves at floor $F$ obtained in wind tunnel tests are used to validate the computer models employed in the simulations. The detailed comparisons between the test (M1, M2 and M3) and simulation (S1, S2, S3) for individual wind directions (cases 1) are shown in Figs.3-4, respectively. It can be seen from the figures that, except for the slight difference between M 1 and $\mathrm{S} 1$ found in case 1 and between $\mathrm{M} 2$ and $\mathrm{S} 2$ found in case 2 , there is generally very good agreement between the test and simulation results. This demonstrates that the numerical models employed in the simulations are reliable and appropriate, and thus can be used to do the comprehensive analysis for the wind characteristics of the building with and without opening. 


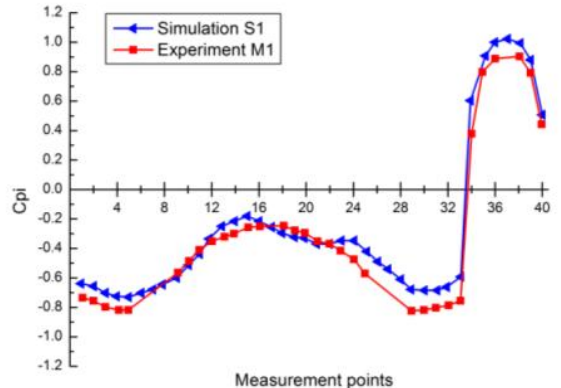

(a)

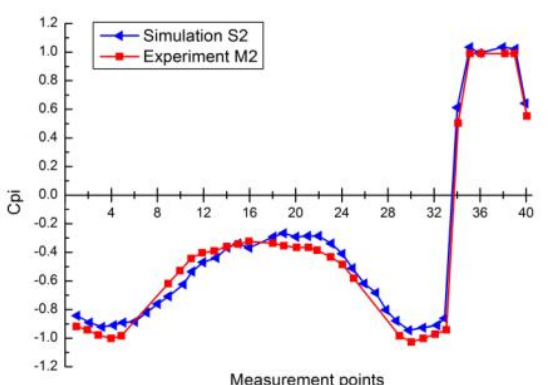

(b)

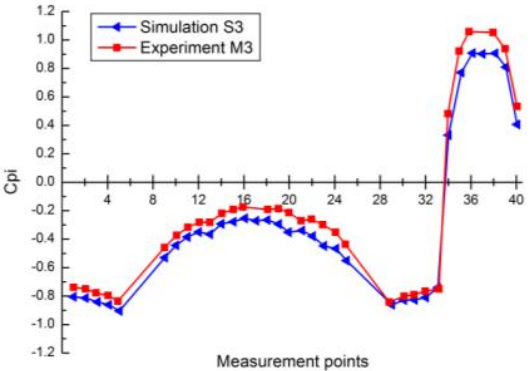

(c)

Figure 3. Comparison of wind pressure coefficients at story F bet ween (a) M1 and S1, (b) M2 and S2, and (c) M3 and S3 for case 1 wind direction

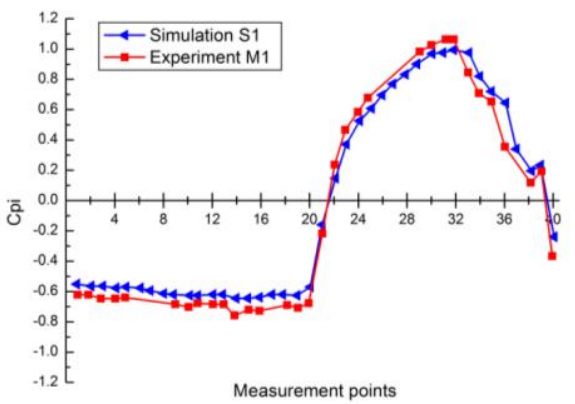

(a)

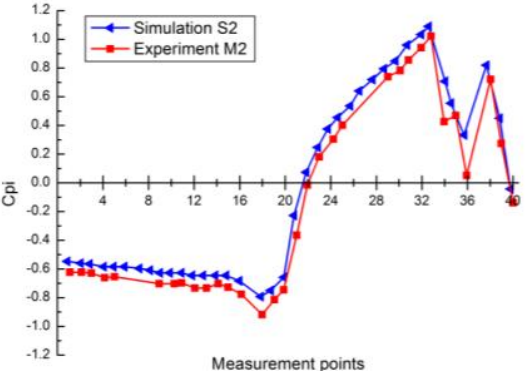

(b)

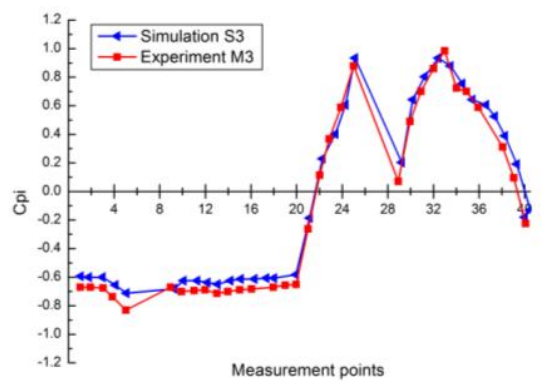

(c)

Figure 4. Comparison of wind pressure coefficients at story F between (a) M1 and S1, (b) M2 and S2, and (c) M3 and S3 for case 2 wind direction

\section{B. Wind Characteristics Analysis}

Fig. 5 shows the wind speed distribution along the front line of the build ing where the opening is located, when a $45^{\circ}$ wind is applied to the building. Fig.5(a) is for the case M2 and Fig.5(b) is for the case M3, respectively. The six curves in each figure represent the buildings with an identical opening but located at different heights. The wind speed plotted in the figures is at the height where the opening is located but the value has been normalized using the wind speed at the roof. It can be seen from Fig.5(a) that the higher wind speed is found in the region where the opening is

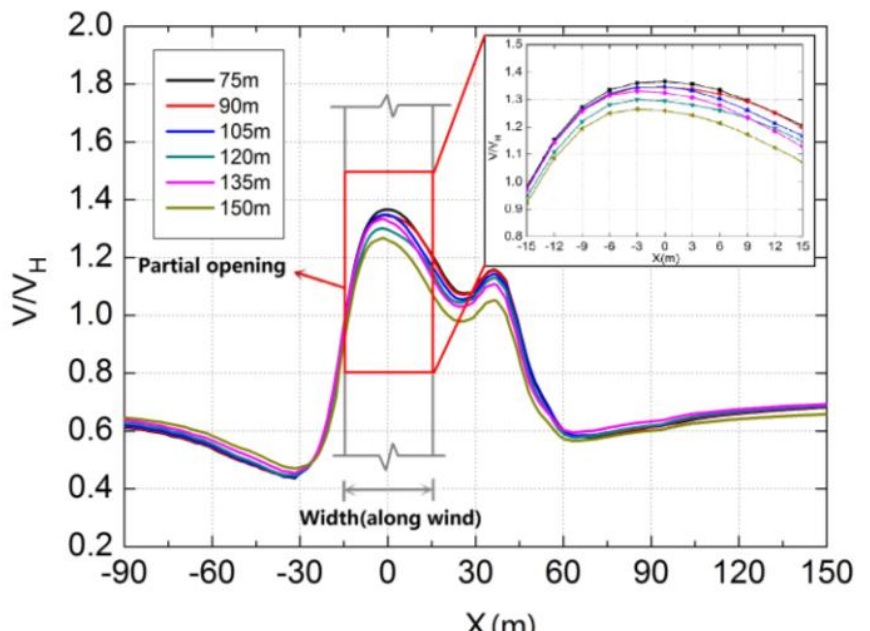

(a) located. The largest wind speed in each curve is found near the center of the opening. It is interesting to notice that, the lower the opening is located, the higher the largest wind speed. Also, it can be observed from Fig.5(a) that, the wind speed increases very quick when it reaches the opening, but decreases slowly when it leaves from the opening. For the building with the opening located at its long side, however, the wind speed distribution (see Fig.5(b)) seems to be different from that in the building with the opening located at its short side (i.e. Fig.5(a))

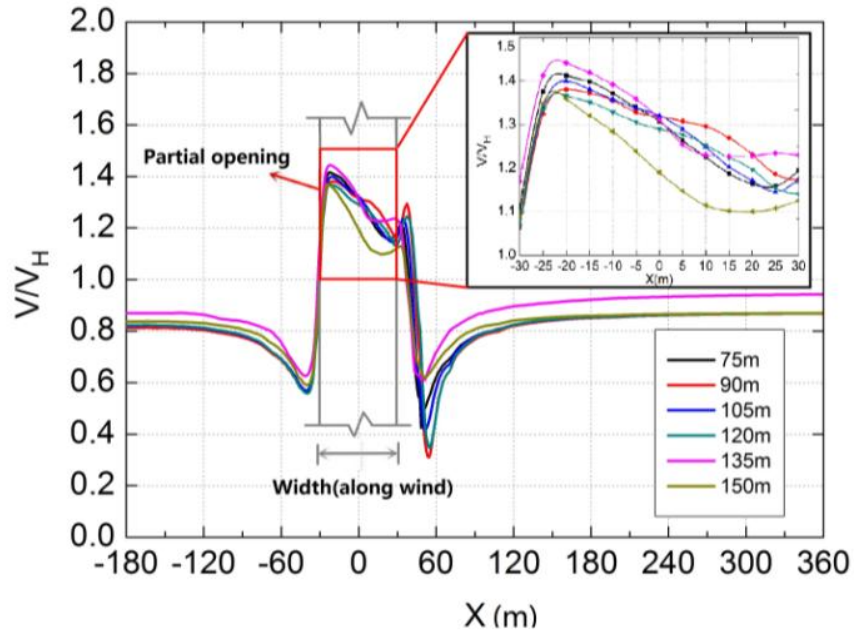

(b)

Figure 5. Wind speed distribution. (a) Along the short side of building where there is an opening. (b) Along the long side of building 
Firstly, the increase and decrease of the wind speed at the two edges of the opening are very quick. Secondly, the largest wind speed in each curve is found near the edge where the wind arrives first. Thirdly, the highest wind speed is when the opening is located at $135 \mathrm{~m}$ high. Fourthly, the largest wind speeds for building with an opening located in the long side of the building are about $1.38-1.44 \mathrm{~V}_{\mathrm{H}}$, while the largest wind speeds for building with an opening located in the short side of the building are about $1.25-1.35 \mathrm{~V}_{\mathrm{H}}$. These differences may reflect the effects of both the opening and the relative size between the building and the opening.

In order to investigate the effect of the width of the opening on the wind flow, Fig. 6 provides a comparis on of the components of wind speed along the central line direction of the opening for three different opening widths (S3, S4 and S5) when the wind is applied to the building by $45^{\circ}$ (i.e. case 2). In Fig. $6, V_{0}$ is the wind speed at the top of S1. $V_{X}$ is the wind speed of along-wind direction. It can be seen from the figure that, for all three opening widths discussed the wind speed along the opening direction exhibits the attendance of an increase followed by a decrease. The peak point is located somewhere behind the midpoint. By comparing the largest values in S3, S4 and S5, it is found that, the wider the opening, the lower the wind velocity.

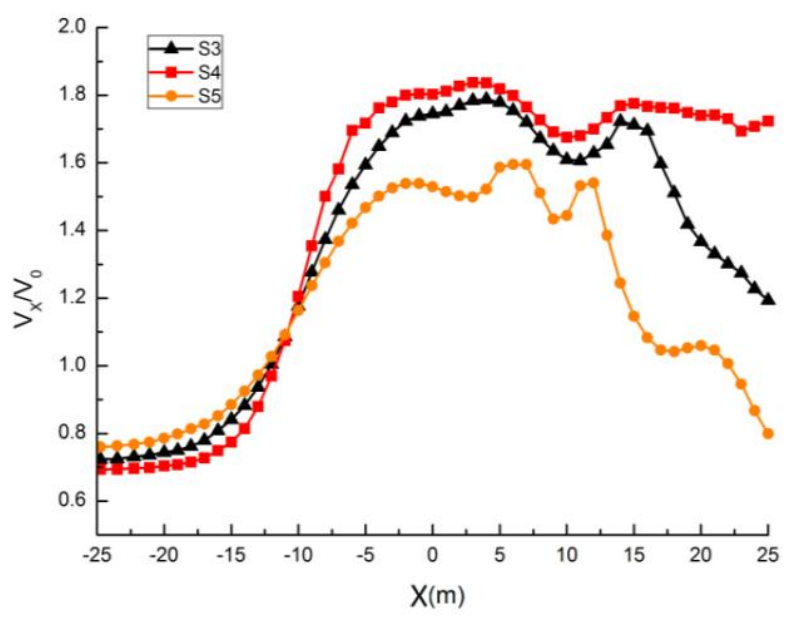

Figure 6. The variation of wind speed component in opening direction along the central axis of the opening for wind direction of $45^{\circ}(\mathrm{H}=135 \mathrm{~m})$

\section{CONCLUSIONS}

In this paper, both experimental tests and numerical simulations have been applied to investigate the aerodynamic characteristics of high-rise buildings with partial opening. The test result showed that the wind speed around the opening increases remarkably and the characteristic of surrounding wind field is affected in large by the partial opening. The pressure coefficients on the two sides of the opening showed an opposite distribution trend: increase on one side but decrease on the other side. On the windward, the opening in the wall only affects the distribution of pressure coefficients and the size of influenced area is close to the size of the opening itself. The pressure coefficients are strongly affected by the opening in the wall when the incoming flow with $\theta=45^{\circ}$, especially on sides of the leeward which is the most harmful case.

The numerical simulation was taken under the same cases with the wind tunnel tests. Good agreement between the numerical simulation and wind tunnel test has been demonstrated. The parametric study on the position and dimension of the opening showed that the $45^{\circ}$ wind direction generates a large wind speed within the opening along the opening direction. The results also showed that the wider the opening, the large the wind speed. This suggests that wind energy resources can be exploited in high-rise building by using wind energy generator placed inside the opening if the position and size of the opening are properly designed.

\section{ACKNOWLEDGMENT}

This research was supported by Zhejiang Provincial Natural Science Foundation of China under Grant No. LY15E080023.

\section{REFERENCES}

[1] A. Kareem, "Dynamic response of high-rise buildings to stochastic wind loads," Journal of Wind Engineering and Industrial Aerodynamics 1992; 42:1101-1112.

[2] K. K. Dae and A. Kareem, "Comparative study of major international wind codes and standards for wind effects on tall buildings," Engineering Structures 2013; 51:23-35.

[3] J. Katagiria,T. Ohkumab and H. Marikawaa, "Motion-induced wind forces act ing on rectangular high-rise buildings with side ratio of 2," Journal of Wind Engineering and Industrial Aerodynamics 2001; 89:1421-1432.

[4] J. D. Holmes. "Mean and fluctuating internal pressure induced by wind," Wind Engineering Proceedings of the Fifth International Conference 1979; 1:435-450.

[5] T. Ho, D. Surry, D. Morrish and G A. Kopp, "The UWO contribution to the NIST aerodynamic database for wind loads on low buildings," Journal of Wind Engineering and Industrial Aerodynamics 2005; 93:1-30.

[6] R. N. Sharma and P. J. Richards, "Computational modeling of the transient response of building internal pressure to a sudden opening," Journal of Wind Engineering and Industrial Aerodynamics 1997; 72:149-161.

[7] L. J. Lo and A. Novoselac, "Cross ventilation with small openings: Measurements in a multi-zone test building," Building and Environment 2012; 57:377-386.

[8] J. Seifert, Y. G Li, J. Axley and M. Rosler, "Calculation of wind-driven cross ventilation in buildings with large openings," Journal of Wind Engineering and Industrial Aerodynamics 2006; 94:925-947.

[9] M. Bayoumi, D. Fink and G Hausladen, "Extending the feasibility of high-rise façade augmented wind turbines," Energy and Buildings 2013; 60:12-19.

[10] L. Lu and K. Sun, "Wind power evaluation and utilization over a reference high-rise building in urban area," Energy and Buildings 2014; 68:339-350.

[11] Q. S. Li, J. Y. Fu, Y. Q. Xiao, Z. N. Li, Z. H. Ni, Z. N. Xie and M. Gu, "Wind tunnel and full-scale study of wind effects on China's tallest building" Engineering Struct ures 2006; 28:1745-1758.

[12] C. M. Chan, M. F. Huang and K. C. Kwok, "Integrated wind load analysis and stiffness optimization of tall buildings with 3D modes [J], "Engineering Structures 2010. 32:1252-1261.

[13] T. K. Guhan, R. N. Sharma and P. J. Richards, "Internal pressure dynamics of leaky building with a dominant opening [J]," Wind 
Engineering and Industrial Aerodynamics, 2011;99:1151-1161.

[14] K. M. Lam, J. G. Zhao and M. Y. Lenung, "Wind-induced loading and dynamic responses of a row of tall buildings under strong interference [J]," Journal of Wind Engineering and Industrial Aerodynamics 2011; 99:573-583.

[15] G Ming, P. Huang, L. Tao, X. Y. Zhou and Z. Fan, "Experimental study on wind loading on a complicated group-tower," Journal of Fluids and Structures 2010;26:1142-1154.
[16] Q. S. Li, F. B. Chen, Y. G Li and Y. Y. Lee, "Implementing wind turbines in a tall building for power generation [J]," Journal of Wind Engineering and Industrial Aerodynamics 2013; 116:70-82.

[17] R. Ramponi and B. Blocken. "CFD simulation of cross-ventilation for a generic isolated building: Impact of computational parameters" Building and Environment 2012; 53:34-48.

[18] Fluent Inc, FLUENT Users Guide. Fluent Inc., 2003. 